\title{
A case of allogeneic hematopoietic stem cell transplantation for primary plasma cell leukemia after treatment with daratumumab
}

\section{$\operatorname{AUTHOR(S):~}$}

Horisawa, Yoshihito; Kondo, Tadakazu; Hishizawa, Masakatsu; Yamashita, Kouhei; Takaori-Kondo, Akifumi

\section{CITATION:}

Horisawa, Yoshihito ... [et al]. A case of allogeneic hematopoietic stem cell transplantation for primary plasma cell leukemia after treatment with daratumumab. Annals of Hematology 2020, 99: 2699-2701

\section{ISSUE DATE:}

2020-11

URL:

http://hdl.handle.net/2433/259191

\section{RIGHT:}

This is a post-peer-review, pre-copyedit version of an article published in Annals of Hematology. The final authenticated version is available online at: http://dx.doi.org/10.1007/s00277-020-04029-y; The full-text file will be made open to the public on 21 April 2021 in accordance with publisher's 'Terms and Conditions for Self-Archiving'.; This is not the published version. Please cite only the published version.; この論文は出版社版でありません。引用の際には出版社版 をご確認ご利用ください。 
1 A case of allogeneic hematopoietic stem cell transplantation for primary plasma

2 cell leukemia after treatment with daratumumab

3

4 Yoshihito Horisawa $^{1}$, Tadakazu Kondo ${ }^{1 *}$, Masakatsu Hishizawa ${ }^{1}$, Kouhei Yamashita $^{1}$,

$5 \quad$ Akifumi Takaori-Kondo ${ }^{1}$

$6 \quad{ }^{1}$ Department of Hematology and Oncology, Graduate School of Medicine, Kyoto

7 University, Kyoto, Japan

8 * To whom correspondence should be addressed: Tadakazu Kondo, Department of

9 Hematology and Oncology, Graduate School of Medicine, Kyoto University

1054 Shogoin Kawaharacho Sakyo-ku, Kyoto 606-8507, Japan

11 Tel: +81-75-751-4946; FAX: +81-75-751-4963; E-mail: tadakazu@kuhp.kyoto-u.ac.jp

13 Running title: Allogeneic transplantation after treatment with daratumumab

14 Key words: primary plasma cell leukemia, daratumumab, allogeneic hematopoietic

stem cell transplantation 
Dear Editor,

Plasma cell leukemia (PCL) is a variant of multiple myeloma (MM), and it is defined

by the presence of more than $20 \%$ of plasma cells in peripheral blood and an absolute plasma cell count greater than $2 \times 10^{9} / 1[1]$. Because primary PCL (pPCL), a PCL subtype without evidence of previous MM, shows frequent early treatment failure and poor prognosis [2], hematopoietic stem cell transplantation (HCT) should be considered . However, although it is reported that autologous and/or allogeneic stem cell transplantation improves pPCL outcomes [3], an appropriate strategy of HCT for pPCL remains elusive.

Here, we report about a patient who underwent allogeneic HCT (allo-HCT) for pPCL that was treated using salvage chemotherapy with daratumumab. To our knowledge, this is the first report of allo-HCT after treatment with daratumumab.

A 47-year-old Japanese man presented with lower back pain and right vision deterioration, which was diagnosed as central retinal vein occlusion by an ophthalmologist, and he was referred to the previous hospital. He was diagnosed with immunoglobulin (Ig) A-kappa-type PCL based on the following laboratory data: white cell blood count, $22200 / \mu \mathrm{l}$ with $87.0 \%$ lymphocytes that were mostly abnormal plasmacytes; serum IgA level, 5904 mg/dl; and serum free kappa/lambda ratio, 166.47. Bone marrow aspiration showed 78.8\% plasmacytes, and the karyotype was 46, inv (Y) (p11.2; q11.2). An interphase fluorescence in situ hybridization study revealed that $\mathrm{t}$ $(11 ; 14)$ was positive but t $(4 ; 14)$, t $(14 ; 16)$, del (13), and del (17) were negative. After four cycles of bortezomib, lenalidomide, and low-dose dexamethasone (VRd) by the previous doctor, he was referred to our hospital for HCT. Laboratory test results on admission were as follows: white blood cells, 3940/ $\mu 1$ without abnormal plasmacytes; 
hemoglobin, $13.7 \mathrm{~g} / \mathrm{dl}$; platelet count, $21.1 \times 10^{4} / \mu \mathrm{l}$; IgG, $282 \mathrm{ml} / \mathrm{dl} ; \mathrm{IgM}, 25 \mathrm{mg} / \mathrm{dl}$; IgA, 475 mg/dl; and serum free kappa/lambda ratio, 10.31. Bone marrow aspiration showed 1.8\% plasmacytes, and complex karyotype with t $(11 ; 14)$ was noted (Fig 1).

After the patient's admission to our hospital, VRd therapy was continued. Because bone marrow aspiration after five cycles of VRd revealed an increase in abnormal plasmacytes, we concluded that the disease was refractory to VRd. Therefore, the chemotherapy regimen was changed to daratumumab, lenalidomide, and low-dose dexamethasone (DRd), following which the abnormal plasmacytes in the bone marrow decreased again. After two cycles of DRd, high-dose melphalan $\left(100 \mathrm{mg} / \mathrm{m}^{2}\right.$ for 2 consecutive days) with autologous stem cell transplantation (ASCT) was performed, and a stringent complete remission was achieved. After ASCT, DRd therapy was continued for six cycles in total.

We decided to perform allo-HCT for three reasons: first, on stem cell mobilization, we harvested only $1.75 \times 10^{6} / \mathrm{kg}$ of CD34-positive cells that were not sufficient for tandem ASCT; second, a suitable human leukocyte antigen-matched unrelated donor was found; and finally, the patient's general state was good even after ASCT.

The patient underwent human leukocyte antigens 8/8 full-matched unrelated bone marrow transplantation with a conditioning regimen of fludarabine $\left(25 \mathrm{mg} / \mathrm{m}^{2}\right.$ for 5 consecutive days), melphalan (70 mg/ $\mathrm{m}^{2}$ for 2 consecutive days), and 8-Gy total body

64 irradiation. This treatment was based on a previous report that demonstrated the

65 feasibility of a myeloablative-conditioning regimen for MM patients after ASCT [4]. For graft-versus-host disease (GVHD) prophylaxis, tacrolimus and methotrexate were used. 
aspiration revealed a complete donor chimerism on day 31. No acute GVHD symptoms appeared, and the patient was discharged on day 50. Primary PCL remained in stringent complete remission 18 months after allo-HCT.

Daratumumab is a human CD38 monoclonal antibody that targets CD38-expressing myeloma cells and has a high therapeutic effect in patients with myeloma [5]. In fact, in a POLLUX study, a phase 3 trial of combination with daratumumab therapy showed that DRd prolongs the progression-free survival of patients with relapsed or refractory MM compared with lenalidomide and DRd therapy [6]. However, the use of daratumumab as a consolidation or salvage therapy before allo-HCT has not yet been reported. Although a clinical trial of daratumumab-containing regimen for patients with newly diagnosed myeloma before ASCT has been reported [7], the safety and efficacy of allo-HCT after daratumumab therapy remains unclear.

CD38 is not only expressed by myeloma cells but also on normal myeloid progenitor cells and lymphocytes [8]. Therefore, in allo-HCT, daratumumab can kill CD38-positive myeloid cells and regulatory T cells from the donor's bone marrow [9-10], which can cause an increase in the rate of graft failure and acute GVHD. However, previous studies reported that daratumumab in vitro is not toxic to CD34- and CD38-positive cells mobilized from patients with myeloma [11], and daratumumab administered as a salvage therapy in patients with relapsed or refractory MM after allo-HCT does not increase the GVHD rate [12], and this supports the safety of using daratumumab before allo-HCT.

In conclusion, we described a case of pPCL that was successfully treated with alloHCT after salvage therapy with daratumumab for the first time. Faster engraftment was achieved, and no acute GVHD was encountered, suggesting that daratumumab had no adverse effect on the prognosis of allo-HCT. To evaluate the efficacy and safety of 
daratumumab before allo-HCT, further analysis with a larger number of patients must be

94 conducted.

95

96 Acknowledgements

97 We are grateful to the medical, nursing, and laboratory staff of the participating departments for their contributions to this study.

99

100 Author Contributions: All authors were involved in the treatment and follow-up of the

101 patient. YH and TK wrote the manuscript and its final version was reviewed and

102 approved by all authors.

\section{Compliance with ehical standards}

105 Ethical approval: All procedures performed in studies involving human participants were in accordance with the ethical standards of the institutional and/or national research committee and with the 1964 Helsinki declaration and its later amendments or comparable ethical standards.

Funding: none

110 Conflict of interest: The authors declare no conflicts of interest.

111 Informed consent: Informed consent was obtained from the patient included in the 112 study. 
115 1. Fernández de Larrea C, Kyle RA, Durie BG, Ludwig H, Usmani S, Vesole DH, et al

116 (2012) Plasma cell leukemia: consensus statement on diagnostic requirements, 117 response criteria and treatment recommendations by the International Myeloma $118 \quad$ Working Group. Leukemia. 27(4): 780-91.

119 2. Gonsalves WI, Rajkumar SV, Go RS, Dispenzieri A, Gupta V, Singh PP, et al (2014)

120 Trends in survival of patients with primary plasma cell leukemia: a population-based analysis. Blood. 124(6): 907-12.

3. Mahindra A, Kalaycio ME, Vela-Ojeda J, Vesole DH, Zhang MJ, Li P, et al.(2012) Hematopoietic cell transplantation for primary plasma cell leukemia: results from the Center for International Blood and Marrow Transplant Research. Leukemia. 26(5): 1091-1097.

4. Shingaki S, Tsukada N, Ishida T, Suzuki K (2018) Feasibility of myeloablative allogeneic hematopoietic cell transplantation from unrelated donors for patients with relapsed or refractory multiple myeloma. Hematological Oncology. 36(1): 363-365.

5. de Weers M, Tai YT, van der Veer MS, Bakker JM, Vink T, Jacobs DC, et al. (2011) Daratumumab, a novel therapeutic human CD38 monoclonal antibody, induces killing of multiple myeloma and other hematological tumors. J Immunol. 186(3): 1840-1848. Daratumumab, lenalidomide, and dexamethasone for multiple myeloma. N Engl J Med. 375(14): 1319-1331.

7. Moreau P, Attal M, Hulin C, Arnulf B, Belhadj K, Benboubker L, et al. (2019) Bortezomib, thalidomide, and dexamethasone with or without daratumumab before 
8. Sieff C, Bicknell D, Caine G, Robinson J, Lam G, Greaves MF. (1982) Changes in cell

140 surface antigen expression during hemopoietic differentiation. Blood. 60(3): 703-713

141 9. Krejcik J, Casneuf T, Nijhof IS, Verbist B, Bald J, Plesner T, et al. (2016) Daratumumab 142 depletes CD38+ immune regulatory cells, promotes T-cell expansion, and skews T-cell 143 repertoire in multiple myeloma. Blood. 128(8): 384-94.

144 10. Krejcik J, Frerichs KA, Nijhof IS, van Kessel B, van Velzen JF, Bloem AC, et al. 145 (2017) Monocytes and Granulocytes Reduce CD38 Expression Levels on Myeloma 146 Cells in Patients Treated with Daratumumab. Clin Cancer Res. 23(24): 7498-7511.

147 11. Ma X, Wong SW, Zhou P, Chaulagain CP, Doshi P, Klein AK, et al. (2018) 148 Daratumumab binds to mobilized CD34+ cells of myeloma patients in vitro without 149 cytotoxicity or impaired progenitor cell growth. Exp Hematol Oncol. 7: 27.

12. Evgeny Klyuchnikov, Ute-Marie von Pein, Francis A. Ayuk, Maximilian Christopeit, and Safe Salvage Therapy in Relapsed/Refractory Patients with Multiple Myeloma after Allogeneic Stem Cell Transplantation. Blood. 128(22): 3437.

\section{Figure legends}

156 Figure 1. Clinical course until allogeneic hematopoietic stem cell transplantation 